\title{
IMPACT OF EXTRACURRICULAR IN THE IMPROVEMENT OF HIGHER EDUCATION GRADUATES' EMPLOYABILITY SKILLS: THE CASE OF TUNISIA
}

\author{
Haifa Mefteh \\ Faculty of Economics and Management of Sfax, Tunisia \\ haifamefteh@yahoo.fr
}

\begin{abstract}
This paper investigates the impact of extracurricular activities (ECA) on developing employability skills of higher education graduates in Tunisia. In this regard, we use a quantitative survey that has been distributed to 451 graduates. The results of the logistic regression model show that participation in extracurricular activities (ECA) is the main determinant of soft skills development. In addition, Spearman's correlation analysis demonstrates a positive one between the acquisition of soft skills and participation in extracurricular activities. Each of the activities develops specific skills. We found that participation in social groups helps to develop more soft skills.
\end{abstract}

Keywords: soft skills, employability skills, graduates, ECA, Tunisia.

DOI: https://doi.org/10.24818/beman/2021.11.1-06

\section{INTRODUCTION}

Higher education's economic purpose has been stated, inter alia, in the purpose of the graduates' employability. Many universities give employability a major attention as it concerns both students and other stakeholders (Knight \& Yorke 2004, Tharunya \& Kottawatta 2014, Sin \& Neave 2016).

The student to employee transition is often tough. This transition is considered competitive, especially when there is a high rate of unemployment and particularly for the best "graduate" jobs where candidates have to excel, and it is filled with uncertainty (Hinchliffe \& Jolly, 2011, Clark et al., 2015).

Today, several universities have begun developing work-related skills for students in their institutions using an assortment of strategies within the curriculum ranging from internships, work placements, and work-integration learning pedagogies (Lau et al., 2014, Roulin and Bangerter 2013, Thompson et al., 2013, Al-Ansari et al.; Tran, 2017). 
Nevertheless, the problem is that HE curricula are already overloaded. As a result, the inclusion of more skills-based subjects reduces the time devoted to specialized subjects. (Al-Mahmood and Gruba, 2007; Tran, 2017).

Based on a quantitative study that tracked a cohort of 451 graduates in Tunisia, this paper aims to assess the perception of higher education graduates to realize the benefits of participating in extracurricular activities (ECAs) during their university curriculum on their soft skills.

\section{LITERATURE REVIEW}

Participating in extra-curricular activities has been linked, empirically, to better employability and graduate results (Kinash et al., 2015) through handing students with an "extra string to their bow" (Thompson et al. 2013, Harvey et al., 2017). Thus, extracurricular activities (ECAs) are encouraged in HEls (Chua et al., 2017).

In general, taking part in extra-curricular activities is linked with enhanced employability and graduate results. Qualitative research with former graduates has found that social connections created through extra-curricular activities benefit graduates finding jobs and developing their chosen professions (Stuart et al., 2011).

Chua et al., 2017 stated that the lack of skills of university students can be rewarded by their participation in ECAs that provide qualities that are not available in the regular curriculum, which affects their employability in the labor market. Studies on the advantages of precise ECAs have shown that student participation in ECAs as a whole is positively associated with the growth of their employability skills and employment consequences (Al-Ansari et al., 2016; Lau et al 2014, Roulin and Bangerter 2013, Thompson et al., 2013).

Additionally, there is little time for students to actually engage in ECA since most of them have to study and work (Clark et al., 2015, Thompson et al., 2013). Moreover, in most ECAs students are only playing the role of simple partakers; therefore, the relevance or way these activities are organized may also impact student involvement (Al-Ansari et al., 2016). Finally, external stakeholders' support, such as local people, industries or authorities, is essential as most ECAs are local community related. Deprived of their support, ECAs can only happen on campus, deterring the development of employability skills in real-world settings.

Some studies show a positive relationship between extracurricular participation at the secondary and university level and some aspects of student personal development (Shahiri \& Adnan, 2015, Wheatley \& Bickerton, 2017, Nghia, 2017). In this regard, Nghia (2017) examined the contribution of extracurricular activities to the development of generic skills for Vietnamese university students. The results indicate 
that extracurricular activities are an integral part of the university's strategy in training generic skills students. This is a result of the lack of curriculum autonomy, which prevents most Vietnamese universities from adding skills subjects to the curriculum.

In addition, Cicekli (2013) reviewed literature which provided a list of qualifications that employers require from graduates who offer their applications to companies. These skills include, among some others, communication, interpersonal skills and teamwork, leadership skills, cognitive skills. Soft skills are now more and more requested in the world of work. These essential qualities were collected from prior studies that focus on non-technical skills that Human Resources seek from new graduates (Chua et al., 2017).

Based on a 3-year longitudinal study tracking a cohort of 40 undergraduates through their student life cycle, Hordósy and Clark (2018) examined how students in a northern English red brick university grasped the aims of ECA, and the way they chose to engage with it. The results show ECAs appear to be somewhat arranged in terms of timeliness of engagement and motivation to participate. Furthermore, the paper claims that those early trials to measure and use ECA to narrate future 'global' employability are likely to replicate well-established disparities. Intrinsically, any further pressure to engage with ECAs exclusively in terms of employability could result in further marginalization of lower-income students.

Despite the importance of ECAs to improve employability of graduates, the effects of several extracurricular activity participations on the employability skills of new graduates have not been meticulously investigated and reported to higher educational institutions. In the present study we investigated the effect of ECAs, including social activities, voluntary work, sports, art and music on employability skills of new graduates, such as oral communication, motivation, problem solve, independence, leadership, creativity, adaptability and flexibility. We hypothesized that new graduates who had been central affiliates in ECAs were more likely to positively rate their employability than were students without such affiliation.

\section{METHODOLOGY}

The data was gathered from higher education graduates five regions in Tunisia. After analyzing the data collected from each respondent, we opted for an econometric analysis of the results. We used the binary logit model to derive the relationship between ECAs and the probability of increasing skill levels in soft skills, among other control variables. Then, a correlation analysis was used to define the rapport between each extracurricular activity and the skills that can develop. The statistical analyses were done using programs SPSS 20. 
This design was used to evaluate the influence of extracurricular activities' involvement on graduate employability in Tunisia between 2016 and 2017.

The study targets were graduate students including males and females who graduated from Universities in Tunisia with a total of 451 graduates $(N=451)$ randomly selected in various fields of study. Graduates included in this study were graduated between 2014-2016, considered as new graduates, since the survey was conducted in 2016 and 2017.

In this work, survey instruments were developed to collect data to answer specific questions, to analyze the perceived ECAs participation among graduates. All participants completed an online questionnaire to assess graduates' participation in ECAs and satisfaction with their soft skills acquisition.

\section{DATA RESULTS AND ANALYSIS}

H1: Being a member of an ECA has a significant impact on the development of employability skills.

The effects of the model include participation in specific ECAs (Social Groups, Voluntary Work, Art I Music, Sport) and the dependent variables are the cumulative average of the thirteen soft skills studied in this paper.

To test the relationship between ECAs and employability skills development, we used a logistic regression:

To further understand the variables' effect identified on the probability of increasing skill levels in soft skills, a single equation probit model was estimated to examine the effect of identified factors affecting the probability of increasing soft skills for the graduates. The data gathered through the surveys cover a range of explanatory variables that may influence the probability of increasing soft skills for graduates (e.g. gender, degree granting institution, field of study, etc). The probit model estimating the probability of increasing soft skills for graduates is expressed as follows:

$$
Y_{i}=\beta_{0}+\beta_{i} X+\varepsilon
$$

Where $Y_{i}=$ the probability of having a high level of soft skills, $X$ is a vector of explanatory variables,

$\beta$ denotes a vector of parameters of explanatory variables to be estimated, and $\varepsilon$ is a vector representing the stochastic error term.

In this study, $(Y)$, as a dependent variable, is measured as a binary variable taking the value 1 if the individual is successful in acquiring a high level of soft skills and 0 if the individual has a low level of soft skills. 
Based on the binary nature of the dependent variable, a binary logistic regression technique was adopted to analyze how each of the explanatory variables can influence the probability that an individual will obtain a high level of soft skills. The logistic model to be estimated for this study is specified as follows:

The logistic model to be estimated for this study is specified as follows:

$\ln \ln \left(\frac{P_{i}}{1-P_{i}}\right)=\beta_{0}+\beta_{1} X_{1}+\beta_{2} X_{2}+\beta_{3} X_{3}+\beta_{4} X_{4}+\beta_{5} X_{5}+\beta_{6} X_{6}+\beta_{7} X_{7}+\beta_{8} X_{8}+$ $\beta_{9} X_{9}+\beta_{10} X_{10}+\beta_{11} X_{11}+\beta_{12} X_{12}+\varepsilon$

Where: $Y=$ skill level in soft skills (high level $=1$, low level $=0$ ). The skill level is expressed as a probability function $\left(\frac{P_{i}}{1-P_{i}}\right)$, with $P_{i}$ indicating the probability that the $i^{\text {th }}$ young has a high skill level and $1-P_{i}$ is the probability that the $i^{\text {th }}$ respondent has a low skill level from the survey data.

$X_{1}$ indicates the respondent's gender, 1 if a woman and 0 if a man; $X_{2}$ indicates the location of the respondent; $X_{3}$ indicates the respondent's field of study; $X_{4}$ indicates the nature of the degree of the individual; $X_{5}$ denotes the nature of the university; $X_{6}$ indicates the entity attended by the graduate; $X_{7}$ indicates the internship experience during the university curriculum; $X_{\mathrm{g}}$ indicates the level of academic training quality; $X_{9}$ indicates the graduate's participation in the activities of social groups; $X_{10}$ indicates participation in a voluntary activity; $X_{11}$ indicates participation in an art activity and $X_{12}$ indicates participation in a sporting activity.

The regression coefficients that are estimated represent the "odds ratio" - Exp (Bi) which measures the effect of the explanatory variables on the "odds ratio" (the odds ratio is the probability of having a high skill level divided by the probability of owning low skill level, $p$ / 1-p). As for the categorical explanatory variables, if the value of the odds ratio $\operatorname{Exp}(B)$ for a certain category is greater than 1 , the chance of having a high skill level is higher for a participant in that group than for the category of reference. Oppositely, the "odd ratio" of less than 1 indicates the lowest probability of having a high level of skills in comparison with the reference category.

For continuous explanatory variables, Exp (Bi) refers to the estimated multiplicative change in odds for one unit of predictor increase, by controlling the effects of the others. Moreover, a positive predictive coefficient ( $\beta>1$ ) means that the predicted probabilities (odds) increase, as the predictor value 
increases, and a negative coefficient $(\beta<1)$ indicates that the predicted probabilities decrease as the value of the predictor increases.

The maximum likelihood method was performed to measure the numerical values of the binary logistic model parameters. This method has a stronger theoretical appeal compared to the OLS method (Bhat, 2001), because of its aptitude to estimate the nonlinear equation that is associated with the logit binomial model implemented in this study (Garrouste \& Rodrigues, 2014).

For logistic regression, the level of employability skills was noted either high or low because a binary response is required. In the first step, the explanatory variables were incorporated into the analysis to verify if there is a rapport with the dependent variable. We found that the gender variables "GEN", nature of diploma "DIP" and nature of university "UNIV" are not related to the dependent variable when tested with Spearman's correlation test (see Table 1).

The remaining nine (9) variables, namely the region "REG", the field of study "FS", the attended entity "ENT", the internship experience "INT", university training "TRAI", social groups "SG", voluntary work "VW", art and music "AM" and sport "SP" are proposed to develop the model.

TABLE 1. SPEARMAN CORRELATION TEST.

\begin{tabular}{|c|c|}
\hline & SOFT \\
\hline SOFT & 1.000 \\
\hline GEN & 0.075 \\
\hline REG & $0.135^{* *}$ \\
\hline FS & $0.305^{* *}$ \\
\hline DIP & 0.045 \\
\hline UNIV & 0.045 \\
\hline ENT & $0.116^{*}$ \\
\hline INT & $0.324^{* *}$ \\
\hline TRAI & $0.553^{* *}$ \\
\hline SG & $0.278^{* *}$ \\
\hline VW & $0.195^{* *}$ \\
\hline AM & $0.202^{* *}$ \\
\hline SPO & $0.256^{* *}$ \\
\hline
\end{tabular}

** The correlation is significant at the 0.01 level.

* The correlation is significant at the 0.05 level.

Source: Developed for this research (based on survey results)

In the second step, the multi-co-linearity problem was identified by a correlation test. According to this test, no variable has been removed. A binary logistic regression was made to evaluate the influence of 
Mefteh, $\mathrm{H}$.

IMPACT OF EXTRACURRICULAR IN THE IMPROVEMENT OF HIGHER EDUCATION GRADUATES' EMPLOYABILITY SKILLS: THE CASE OF TUNISIA

the explanatory variables on the probability that a young graduate would be equipped with a high level of soft skills. The model containing 9 factors from the sample is presented in Table 2.

In the third step, the predictor variables were advanced for the analysis by using the Binary Logistic regression method and the variables were added in a stepwise method, acknowledged as the Wald method. A variable must be significant at the 0.05 level to enter the model, while it must be significant at 0.10 to stay in the model. Lastly, the model, in step 1 of the analysis, presented in Table 2 identifies the employability skills' determinants.

TABLE 2. BINARY LOGISTICS RESULTS.

\begin{tabular}{|c|c|c|c|c|c|c|c|}
\hline Variables & & $\beta$ & E.T. & Wald & gl & Sig. & $\operatorname{Exp}(\beta)$ \\
\hline \multirow[t]{6}{*}{ Region } & & & & 5.611 & 4 & 0.23 & \\
\hline & Tunis & 0.034 & 0.48 & 0.005 & 1 & 0.943 & 1.035 \\
\hline & Mahdia & 0.696 & 0.423 & 2.710 & 1 & 0.100 & 2.005 \\
\hline & Sidi Bouzid & 0.805 & ,460 & 3.067 & 1 & 0.080 & 2.237 \\
\hline & Sfax & 0.588 & 0.385 & 2.337 & 1 & 0.126 & 1.801 \\
\hline & Gafsa (Ref.) & & & & & & \\
\hline \multirow[t]{8}{*}{ Field } & & & & 18.293 & 6 & 0.006 & \\
\hline & Social Sciences & -0.844 & 0.688 & 1.506 & 1 & 0.220 & 0.430 \\
\hline & Exact Sciences & -1.397 & 0.714 & 3.828 & 1 & 0.050 & 0.247 \\
\hline & $\begin{array}{l}\text { Arts and } \\
\text { Humanities }\end{array}$ & 0.037 & 0.658 & 0.003 & 1 & 0.955 & 1.038 \\
\hline & $\begin{array}{l}\text { Engineering } \\
\text { Sciences }\end{array}$ & 0.262 & 0.763 & 0.118 & 1 & 0.732 & 1.299 \\
\hline & Services & 1.059 & 0.866 & 1.494 & 1 & 0.222 & 2.883 \\
\hline & Health & 0.489 & 0.875 & 0.312 & 1 & 0.576 & 1.630 \\
\hline & Others (Ref.) & & & & & & \\
\hline \multirow{6}{*}{$\begin{array}{l}\text { Nature of } \\
\text { Degree }\end{array}$} & & & & 7.080 & 4 & 0.132 & \\
\hline & $\begin{array}{l}\text { Technician } \\
\text { degree }\end{array}$ & -1.463 & 0.876 & 2.788 & 1 & 0.095 & 0.232 \\
\hline & $\begin{array}{l}\text { Licence/Maitrise } \\
\text { degree }\end{array}$ & -0.503 & 824 & 0.373 & 1 & 0.541 & 0.605 \\
\hline & $\begin{array}{l}\text { Engineering } \\
\text { degree }\end{array}$ & $\begin{array}{l}-1.104 \\
\end{array}$ & 0.925 & 1.425 & 1 & 0.233 & 0.331 \\
\hline & $\begin{array}{l}\text { Postgraduate } \\
\text { degree }\end{array}$ & -0.380 & 0.788 & 0.232 & 1 & 0.630 & 0.684 \\
\hline & $\begin{array}{l}\text { Other degrees } \\
\text { (Ref.) }\end{array}$ & & & & & & \\
\hline \multirow[t]{2}{*}{ Traineeship } & Yes & 0.891 & 0.283 & 9.938 & 1 & 0.002 & 2.438 \\
\hline & No (Ref.) & & & & & & \\
\hline \multirow[t]{2}{*}{ Training } & High & 2.237 & 0.381 & 34.518 & 1 & 0.000 & 9.368 \\
\hline & Low (Ref.) & & & & & & \\
\hline ECA1 & Yes & 2.255 & 0.600 & 14.125 & 1 & 0.000 & 9.540 \\
\hline
\end{tabular}


Mefteh, $\mathrm{H}$.

IMPACT OF EXTRACURRICULAR IN THE IMPROVEMENT OF HIGHER EDUCATION GRADUATES' EMPLOYABILITY SKILLS: THE CASE OF TUNISIA

\begin{tabular}{|l|l|l|l|l|l|l|l|}
\hline & No (Ref.) & & & & & & \\
\hline ECA2 & Yes & 1.798 & 0.730 & 6.066 & 1 & 0.014 & 6.038 \\
\hline & No (Ref.) & & & & & & \\
\hline ECA3 & Yes & 0.438 & 0.652 & 0.451 & 1 & 0.502 & 1.549 \\
\hline & No (Ref.) & & & & & & \\
\hline ECA4 & Yes & 1.590 & 0.462 & 11.831 & 1 & 0.001 & 4.902 \\
\hline & No (Ref.) & & & & & & \\
\hline
\end{tabular}

Source: Developed for this research (based on survey results)

Exp (B) is the odds ratio that indicates the degree to which the odds (probabilities) for a positive response are high when the degree of the associated explanatory variable is high from the reference level to the level specified in the results table.

This study measures the extent to which probabilities in for employability skills are increased when the levels of each explanatory variable move from the reference level (low) to the highest level (high). Hence, it demonstrates that being a member of social groups (ECA1) is the most important determinant of employability skills in soft skills, with a $1 \%$ confidence for $\operatorname{Exp}(B)$ of 9.540 . This shows that those who participate in an activity of social groups have 9.540 times more chance to acquire skills compared to those who do not participate in these activities.

The quality of the training (TRAI) is the second determining factor since $\operatorname{Exp}(B)$ has a value of 9,368 . In addition, participating in voluntary work (ECA 2) is an important determinant of employability of graduates with an odds ratio of 6.038. Similarly, being a member of a sports activity (ECA 4) increases the chance of having a high skill level with odds of 4.902 . However, being a member of arts activities (ECA 3) was not important to include in the model as a determinant of skill development.

Another determining factor that has a positive impact on increasing the skill level is the Placement Experience (INT). Thus, the internship experience allows students to upgrade their skill level by 2.438 times higher.

However, factors of region (REG) and nature of diploma (DIP) are not important to include in the model as level determinants of employability skills. On the other hand, we can see that graduates in exact sciences are much less likely $(1 /, 247=4.04)$ to have a high level of skills. Thus, their probability of having a high level of soft skills during their university studies is $4.04(1 / 0.247)$ times lower than the reference variable.

TABLE 3. MODEL SUMMARY.

\begin{tabular}{|c|c|c|c|c|c|c|}
\hline Step & $\begin{array}{c}-2 \text { Log } \\
\text { likelihood }\end{array}$ & $\begin{array}{c}\text { Cox \& Snell R } \\
\text { Square }\end{array}$ & $\begin{array}{c}\text { Nagelkerke R } \\
\text { Square }\end{array}$ & \multicolumn{3}{|c|}{ Hosmer and Lemeshow Test } \\
\hline & & & & Chi-square & df & Sig. \\
\hline 1 & 376.772 & 0.377 & 0.516 & 5.820 & 8 & 0.667 \\
\hline
\end{tabular}

Source: Developed for this research (based on survey results) 
In general, the -2Log Likelihood (-2LL) probability is a measure of mistrust, that illustrates the error that remains in the model after the account for all independent variables. The -2LL of 376.772 indicates that no significant errors remain in the model. Nagelkerke R square (Nagelkerke R) indicates that about $52 \%$ of the variation of the outcome variable (probability of a high level of skills) is explained by the model in step 1. A greater $p$-value of the Hosmer-Leme show test indicates a better concordance to affirm that the model corresponds well to the data. As a result, the model is better in the first step.

The results show that graduates who partook in ECAs in the areas of social groups, voluntary work and sports are more likely to positively assess their employability skills. Our results are resembling the results presented in a study by Lau et al. (2014) for Taiwan business schools, which also reported that students who we rekey members of extracurricular activities are more likely to positively evaluate their communication, leadership, creativity and self-promotion skills.

In addition, the results suggest that the type of activities carried out at universities is still important for professional results and those different sorts of activities exert a substantial effect on different cohorts of graduates. However, the different types of ECA can have an unequal effect on the graduates' employability. Thus, it remains to determine which skills have benefited the most from participation in ECAs and which, thus, are ECAs that generate more employability skills? These questions will be addressed in the next subsection.

$\mathrm{H} 2$ : Diverse types of ECAs could inequitably influence the employability of graduating college students. The strength and direction of the link between two variables are quantified using correlation analysis. Correlation statistically measures the relationship between two or more factors (Chua et al., 2017). It shows the way one factor can influence the other but does not essentially hint that this factor engenders the other. In our work, we used the Pearson correlation provided in SPSS for all independent variables.

The Pearson correlation coefficient varies between positive (+1) and negative (-1). A positive correlation

$(+1)$ indicates an unerring positive relationship while a negative correlation (-1) indicates a perfect negative relationship. A zero ( 0 ) value means that the two variables have no correlation.

Table 4 presents the correlation matrix between ECAs and the skills they can develop that are significant at the 0.05 level.

TABLE 4. CORRELATION ANALYSIS BETWEEN ECA VARIABLES AND SOFT SKILLS.

\begin{tabular}{|l|c|c|c|c|}
\hline & Social groups & Voluntary work & Art / Music & Sport \\
\hline Oral Communication & $0.151^{* *}$ & 0.051 & $0.121^{*}$ & 0.072 \\
\hline Motivation & $0.197^{* *}$ & 0.066 & 0.074 & $0.184^{* *}$ \\
\hline Problem resolution & $0.111^{*}$ & 0.067 & $0.116^{*}$ & 0.073 \\
\hline Teamwork & $0.175^{* *}$ & $0.113^{*}$ & 0.084 & $0.123^{* *}$ \\
\hline Self-confidence & $0.209^{* *}$ & 0.077 & 0.077 & $0.166^{* *}$ \\
\hline
\end{tabular}



EMPLOYABILITY SKILLS: THE CASE OF TUNISIA

\begin{tabular}{|l|c|c|c|c|}
\hline Independence & $0.143^{* *}$ & $0.119^{*}$ & 0.061 & $0.227^{* *}$ \\
\hline Adaptability and flexibility & $0.147^{* *}$ & $0.099^{*}$ & $0.113^{*}$ & $0.136^{* *}$ \\
\hline Willing to learn & $0.171^{* *}$ & 0.079 & 0.045 & 0.092 \\
\hline Planification & $0.179^{* *}$ & 0.063 & 0.035 & $0.102^{*}$ \\
\hline Creativity and Innovation & 0.087 & 0.092 & 0.087 & $0.093^{*}$ \\
\hline Leadership & $0.097^{*}$ & 0.045 & $0.108^{*}$ & $0.148^{* *}$ \\
\hline Initiative & 0.065 & $0.103^{*}$ & $0.146^{* *}$ & $0.187^{* *}$ \\
\hline Working under pressure & $0.213^{* *}$ & 0.018 & 0.079 & $0.201^{* *}$ \\
\hline
\end{tabular}

Source: Developed for this research (based on survey results)

Table 4 shows that graduates who were members of extracurricular activities (social groups, voluntary work, art and music, and sport) are more probable to positively assess their employability in soft skills. Our results show that all skills are significantly affected by participating in extracurricular activities. However, the analytical results show that the experience of being a member of extracurricular activities has unevenly led to the different employability skills. Indeed, although the results revealed that the experience of being a member in the four extracurricular activities can benefit the adaptability and flexibility of graduates, the other skills differ according to the activity in which the graduate participated. For example, participation in social groups can develop all skills except creativity and initiative. On the other hand, graduate participation in voluntary work has the effect of improving teamwork, independence, adaptability and flexibility, and initiative. While participation in art and music activities can develop oral communication, problem solving, adaptability and flexibility, leadership, and initiative. Being a member of a sport activity helps to develop motivation, teamwork, self-confidence, independence, adaptability, flexibility, planning, creativity, leadership, initiative, and work under pressure. Differences can also be observed between the influences of participation on each skill. For example, social groups have a stronger influence on self-confidence $(0.209)$ and motivation $(0.197)$ skills. Voluntary work affects more independence $(0.119)$ and teamwork $(0.113)$ skills. Art/Music activities have a higher impact on the development of the initiative $(0.146)$, oral communication (0.121) and problem solving (0.116) skills. While sports activities offer graduates more opportunities to develop their independence $(0.227)$ and their ability to work under pressure $(0.201)$.

Being a member of extracurricular activities, especially social groups and sports, offers graduates more opportunities to acquire employability skills. In other words, the probability of acquiring more employability skills is higher when students participate in social groups, followed by sports clubs.

Unlike other employability skills, the results show that the willingness to learn $(0.117$ through participation in social groups) and creativity ( 0.093 through participation in sports clubs) benefit less from participation in the ECA. 
Generally, all employability skills are significantly influenced by participation in an extracurricular activity (or more). However, this survey revealed that HE graduates' skills assessments of their willingness to learn and their creativity only benefit slightly from their participation in ECAs.

- The following results were derived from the survey results to describe the overall effect of each extracurricular activity on individual's employability skills:

- The more the graduate is involved in activities of social groups, the more s/he develops skills in oral communication, motivation, problem solving, teamwork, self-confidence, independence, adaptability and flexibility, willingness to learn, in planning, leadership and work under pressure.

- The higher the participation in voluntary work activities, the greater the skills of teamwork, independence, adaptability, flexibility, and initiative.

- The more the graduate is integrated into art and music clubs, the more s/he develops skills in oral communication, problem solving, adaptability and flexibility, leadership and initiative.

- Respondents' level of participation in sport activities can increase their motivation, teamwork, selfconfidence, independence, adaptability and flexibility, planning, creativity, leadership, initiative and working under pressure skills.

However, this survey revealed that employer' assessments of the skills of HE graduates show wide skills gaps. Hence, the way student employability skills are developed remains a central issue for HE.

\section{DISCUSSION AND CONCLUSION}

The main objective of our research is to determine whether involvement in extracurricular activities has an impact on the employability of HE graduates in Tunisia. Firstly, our results show that participation in ECA is the main determinant of the development of soft skills of HE graduates.

The results of this research show, secondly, that there is a positive correlation between the acquirement of employability skills by graduates and their participation in extracurricular activities.

According to the importance given to ECAs, university departments must include them in their curriculum activities which will additionally develop students' soft skills. In addition, the university department should design, develop, and implement a graduate tracking system to facilitate communication with them if their contributions will be needed in future studies. Similarly, current HE students are encouraged to engage in and participate in extracurricular activities if they control and balance their time schedule with their university teachers. So, it does not matter if you are volunteering in the community, doing a placement related to your classes, or even working in a restaurant to earn some pocket money, any job that the graduate doing at the university might be more relevant than he thinks. When applying for almost any job, they will be asked to provide examples of their teamwork, 
communication with others, organization, and motivation. ECAs are an ideal way to gain experience that can be used to demonstrate one's personal skills.

Due the fact that ECAs are often considered "extra" and ignored by students and other stakeholders, university officers should advise students on the importance and role of these extra-curricular activities in the development of their soft skills so that students have the possibility to participate in this kind of informal learning and that other stakeholders can provide support if needed. It is, also, crucial that they allot suitable resources to extracurricular activities relative to the contribution they could.

Make to student skills development programs in higher education. Additionally, constructing connections with external stakeholders such as employers, skills experts, alumni, and local authorities is imperative to develop soft skills for students through this channel as these stakeholders can create more opportunities, by providing staff or resources for learning through extracurricular activities.

To sum up, numerous factors can thwart the effectiveness of skills development programs in higher education institutions, this includes lack of leadership and management, inappropriate teacher ability, student disengagement, lack of resources and lack of support from external stakeholders (de la Harpe and David, 2012; Jackson, 2015; Tran, 2015).

However, it is biased to dismiss the full responsibility of graduates in developing their skills in higher education institutions. First, each graduate or employee's skill level of is dependent on their efforts in developing the relevant skills of their profession.

Students, during their time and academic studies, must comprehend the needs and nature of a targeted profession and endeavor to develop the relevant employability skills (Jackson, 2016).

Unfortunately, several students are only looking for a degree instead of participating in activities existing at the university to acquire tangible competence (Tran, 2015). In addition, for employees, the knowledge and skills acquired during their graduate studies can also be used as a foundation for having access to a profession. They must participate in the ECA in an active way to improve their skills in soft skills, identify their weaknesses in skills to improve them and upgrade their professional identity.

Nevertheless, certain issues necessitate to be given adequate focus to efficiently use these types of activities for implementation.

Finally, it should be noted that this study relied on graduates' perceptions concerning their skills satisfaction. It is recommended that future studies should replicate the study by investigating perceptions of relevant groups of HE stakeholders to reveal an array of perceived influence of extracurricular activities on graduate skills development in Tunisia and replicate the study in different countries to further confirm the findings. 


\section{REFERENCES}

Al-Ansari, A., Al-Harbi, F., AbdelAziz, W., AbdelSalam, M., El Tantawi, M.M., EIRefae, I. (2016). Factors affecting student participation in extra-curricular activities: A comparison between two Middle Eastern dental schools. The Saudi Dental Journal. 28: 36-43.

Al-Mahmood, R., Gruba, P. (2007). Approaches to the implementation of generic graduate attributes in Australian ICT undergraduate education. Computer Science Education. 17(3): 171-185. doi:10.1080/08993400701538054.

Bhat, C.R. (2001). Quasi-random maximum simulated likelihood estimation of the mixed multinomial logit model. Transportation Research Part B. 35(7): 677-693.

Chua, C.J.E., Chuatoco, I.A.G., Dela Peña, A.M.C., Jimenez, D.L.F., Co, D.A. (2017). The influence of participation in extracurricular activities to the employability of Industrial Engineering graduates of one Private University in the Philippines. Asia Pacific Journal of Multidisciplinary Research. 5 (2): 163-170.

Cicekli, E. P. (2013). Human Resources Needs of Organizaions in Terms of the Qualities They Need and Seek from New Graduate Employees. International Journal of Business and Social Science. 4(1): 49-58.

Clark, G., Marsden, R., Whyatt, J. D., Thompson, L., Walker, M. (2015). It's Everything Else You Do..': Alumni Views on Extracurricular Activities and Employability. Active Learning in Higher Education. 16 (2): 133-147.

De la Harpe, B., David, C. (2012). Major influences on the teaching and assessment of graduate attributes. High. Educ. Res. Dev. 31(4): 493-510. DOI: https://doi.org/10.1080/\%2007294360.2011.629361

Garrouste, C.L., Rodrigues, M. (2014). Employability of young graduates in Europe. International Journal of Manpower. 35(4): 425-447.

Harvey, A., Andrewartha, L., Edwards, D., Clarke, J., Reyes K. (2017). Student equity and employability in higher education. Report for the Australian Government Department of Education and Training. Melbourne: Centre for Higher Education Equity and Diversity Research, La Trobe University. February 2017. DOI: 10.13140/RG.2.2.24379.21288.

Hinchliffe, G.W., Jolly, A. (2011). Graduate identity and employability. British Educational Research Journal. 37(4): 563-84.

Hordósy, R., Clark, T. (2018). Beyond the compulsory: a critical exploration of the experiences of extracurricular activity and employability in a northern red brick university. Research in postcompulsory education. 23(3):

414-435. https://www.tandfonline.com/doi/full/10.1080/13596748.2018.1490094

Jackson, D. (2015). Employability Skill Development in Work-integrated Learning: Barriers and Best Practice. $\quad$ Studies in Higher Education. 40(2): 350-367.

Jackson, D. (2016). Re-conceptualising graduate employability: the importance of preprofessional identity. Higher Education Research and Development. 35 (5): 925-939. https://www.tandfonline.com/doi/full/10.1080/07294360.2016.1139551

Kinash, S., Crane, L., Judd, M-M., Mitchell, K., McLean, M., Knight, C., Dowling, D., Schultz, M. (2015). Supporting graduate employability from generalist disciplines through employer and private 
institution collaboration. Report prepared for the Office of Learning and Teaching, Australian Government.

Knight, P., Yorke, M. (2004). Learning, Curriculum and Employability in Higher Education. Edition in Taylor \& Francis e-Library.

Lau, H.-H., Hsub, H.-Y., Acostac, S., Hsu, T.-L. (2014). Impact of participation in extracurricular activities during college on graduate employability: an empirical study of graduates of Taiwanese $\begin{array}{llll}\text { business schools. } & \text { Educational 26-47. }\end{array}$ https://www.tandfonline.com/doi/abs/10.1080/03055698.2013.830244

Nghia, T. (2017). Developing generic skills for students via extra-curricular activities in Vietnamese universities: Practices and influential factors. Journal of Teaching and Learning for Graduate Employability. 8(1): 22-39.

Roulin, N., Bangerter, A. (2013). Student's use of extra-curricular activities for positional advantages in competitive job markets. Journal of Education and Work. 26(1): 21-47.

Shahiri, H., Adnan, S.N. (2015). The Relevancy of Co-Curricular Activities on Graduates Employability: Evidence from a Graduate Unemployment Duration Model. Prosiding perkem. 10: 93 - 98.

Sin, C., Neave, G. (2016). Employability deconstructed: perceptions of Bologna stakeholders. Studies in Higher Education. 41(8):

1447-1462. https://www.tandfonline.com/doi/full/10.1080/03075079.2014.977859.

Stuart, M., Lido, C., Morgan, J., Solomon, L., May, S. (2011). The impact of engagement with extracurricular activities on the student experience and graduate outcomes for widening participation populations. Active Learning in Higher Education. 12(3): 203-215.

Tharunya, S.R., Kottawatta, H. (2014). Perception of Employability Skills of HRM Graduates: From Employers' and Graduates' Perspective. Human Resource Management Journal. 2(1): 11-21.

Thompson, L.J., Clark, G., Walker, M., Whyatt, J. D. (2013). It's Just like an Extra String to Your Bow': Exploring Higher Education Students' Perceptions and Experiences of Extracurricular Activity and Employability. Active Learning in Higher Education. 14(2): 135-147. doi:10.1177/1469787413481129.

Tran, L.H.N. (2017). Developing employability skills via extra-curricular activities in Vietnamese universities: student engagement and inhibitors of their engagement. Journal of Education and Work. 30 (8): 854-867.

Tran, T.T. (2015). Is Graduate Employability the 'Whole-of-higher-education-issue'?. Journal of Education and Work. 28 (3): 207-227. doi:10.1080/13639080.2014.900167.

Wheatley, D., Bickerton, C. (2017). Subjective well-being and engagement in arts, culture and sport. Journal of Cultural Economics. 41(1): 23-45. DOI: 10.1007/s10824-016-9270-0. 